\title{
Video Assisted Informed Consent Process on Level of Satisfaction and Cognition among Patients Undergoing Invasive Therapeutic / Diagnostic Cardiac Procedure
}

\section{Kripa Angeline A*, Renuka K, Bhavithiran K, Bhuvaneshwari M, Dhivya G, Dhivya Bharathi V, Dhivya R \\ Department of Medical and Surgical Nursing, Kasturba Gandhi Nursing College, India}

*Corresponding author: Kripa Angeline, Department of Medical and Surgical Nursing, Kasturba Gandhi Nursing College, Puducherry, India, Email: angelinekripa@gmail.com

\section{Research Article \\ Volume 3 Issue 1}

Received Date: March 05, 2018

Published Date: March 27, 2018

\begin{abstract}
Background: The heart is a vital muscular organ in humans which pumps blood through the body's arteries and veins and the center of body's circulatory system. Healthy arteries enable your body to respond well to periods of stress and changes in your blood pressure. If arteries become narrow or blocked (coronary artery disease, or CAD), heart attack or stroke may occur. People with cardiovascular disease or who are at high cardiovascular risk need early detection and management using counseling and medicines, as appropriate Achieving informed consent for therapeutic /diagnostic procedures is a core clinical procedure. In addition to routine consent process patients are invited to watch the video of the therapeutic/diagnostic procedure to gain knowledge of perspective what is involved and assessed its impact on patient satisfaction.
\end{abstract}

Materials and Methods: True experiments (post test only design) was used for this study and sample size is 80 , with 40 each in experimental and control groups. The cardiology patients were selected from MGMC and RI, puducherry by using simple randomized sampling technique. The data were collected by using structured questionnaire and standardized patient satisfactory tool. The questionnaire consists of multiple choice questions. The period of data collection was around two weeks. For control set of questions were given and ask them to answer the questions. For control group, video was shown related to invasive therapeutic/diagnostic procedures, after a set questions were given and ask them to answer the questions.

Aim: The main aim of the current study was to assess the effectiveness of the patient level of satisfaction and cognition regarding informed consent by routine method and video assisted method for invasive therapeutic/diagnostic procedures and also to compare effectiveness of routine method Vs video assisted method on level of satisfaction and cognition for informed consent among patient undergoing invasive therapeutic/diagnostic procedures. 


\section{Open Access Journal of Pulmonary \& Respiratory Sciences}

Results: The post test score on level of knowledge among patients undergoing invasive therapeutic/diagnostic procedure after video assisted method revealed that 40 had adequate knowledge in experimental group. The post test score on level of satisfaction among patient undergoing invasive therapeutic/diagnostic procedure after vide assisted method revealed that 40 were fully satisfied in experimental group.

Keywords: Effectiveness; Informed consent; Video assisted informed consent; Therapeutic Procedures; Diagnostic Procedures

\section{Introduction}

From the beginning of our life until death the humans works tirelessly, the human heart beats more than two and half billion times during average life time without even pausing to rest. The heart pumps with full force and supplies blood and energy to the body to sustain life. If it stops pumping (or) does not pump with sufficient force life comes to end [1].

The heart is a vital muscular organ in humans which pumps blood through the body's arteries and veins. Healthy arteries enable your body to respond well to periods of stress and changes in the blood pressure. If arteries become narrow or blocked (coronary artery disease, or CAD), heart attack or stroke may occur [2,3].

According to WHO, cardiovascular diseases are the main causes of all over the world. CVDs are the number 1 cause of death globally: more people die annually from CVDs than from any other cause. An estimated 17.7 million people died from CVDs in 2015, representing 31\% of all global deaths. Of these deaths, an estimated 7.4 million were due to coronary heart disease and 6.7 million were due to stroke. Over three quarters of CVD deaths take place in low- and middle-income countries. Out of the 17 million premature deaths (under the age of 70 ) due to non- communicable diseases in $2015,82 \%$ are in low- and middle-income countries, and $37 \%$ are caused by CVDs [4,5]. Most cardiovascular diseases can be prevented by addressing behavioral risk factors such as tobacco use, unhealthy diet and obesity, physical inactivity and harmful use of alcohol using populationwide strategies [6]. People with cardiovascular disease or who are at high cardiovascular risk (due to the presence of one or more risk factors such as hypertension, diabetes, hyperlipidaemia or already established disease) need early detection and management using counseling and medicines, as appropriate. There are many diagnostic procedures for diagnosing cardiovascular diseases such as echocardiogram, a chest X-ray, ECG, Exercise tolerance test angiogram $[7,8]$.

Video assisted teaching improves the patient awareness and satisfaction regarding the procedures. A recent study by University Hospital, Turkey in 2005 and also by Ottava Heart institute 2010 showed that educating patients who are undergoing invasive procedures especially through video creates a real image of what is going to be done for them and makes them more prepared and they accept it better decreasing the complications [9].

\section{Objectives of the Study}

*To assess patient level of satisfaction and cognition regarding informed consent by routine method and video assisted method for invasive therapeutic/diagnostic procedures.

*To compare effectiveness of routine method Vs video assisted method on level of satisfaction and cognition for informed consent among patient undergoing invasive therapeutic/diagnostic procedures.

\section{Methodology}

\section{Research Design}

True experimental post test only design.

\section{Study Setting}

Cardiac ward, Mahatma Gandhi medical college and research institute, pillaiyarkuppam, puducherry.

\section{Population}

Patient undergoing invasive therapeutic/diagnostic procedures in MGMC and RI, pillaiyarkuppam, Pondicherry. 


\section{Sampling Technique}

Simple randomized sampling technique (lottery method).

\section{Sample Size}

Sample size is 80 subjects. 40 in experimental group and 40 in control group.

\section{Data Collection Method}

True experiments (post test only design) was used for this study and sample size is 80, with 40 each in experimental and control groups. The cardiology patients were selected from MGMC and RI, puducherry by using simple randomized sampling technique. The data were collected by using structured questionnaire and standardized patient satisfactory tool. The questionnaire consists of multiple choice questions. The period of data collection was around two weeks. For control set of questions were given and ask them to answer the questions. For control group, video was shown related to invasive therapeutic/diagnostic procedures, after a set questions were given and ask them to answer the questions. Finally analyzed by using evaluative and inferential statistics.

\section{Procedure for Data Collection}

Data collection period was 2 weeks. Before starting the data collection, researchers obtained permission from the concerned authorities. 80 sample based on the inclusion criteria were selected through simple randomized sampling technique. Data was obtained from the patient undergoing invasive therapeutic/diagnostic procedure through structured questionnaire and standardized tool.

\section{Criteria for Sample Selection}

Patient who are

a) Posted for invasive therapeutic/diagnostic procedures.

b) Mentally alert and who will be able to understand or read and write Tamil/English.

c) Undergoing invasive therapeutic/diagnostic procedures for first time.

\section{Results}

\begin{tabular}{|c|c|c|c|}
\hline \multirow[t]{2}{*}{ SI.NO. } & \multirow[t]{2}{*}{ DEMOGRAPHIC VARIABLES } & \multicolumn{2}{|c|}{ FREQUENCY (n) } \\
\hline & & CONTROL GROUP & EXPERIMENTAL GROUP \\
\hline \multirow[t]{6}{*}{1} & AGE & & \\
\hline & below 31 & & \\
\hline & $31-40$ & 9 & 2 \\
\hline & $41-50$ & 3 & 5 \\
\hline & $51-60$ & 5 & 9 \\
\hline & & 16 & 19 \\
\hline \multirow[t]{3}{*}{2} & SEX & & \\
\hline & Male & 15 & 19 \\
\hline & Female & 25 & 21 \\
\hline \multirow[t]{4}{*}{3} & RELIGION & & \\
\hline & hindu & 40 & 35 \\
\hline & christian & 0 & 3 \\
\hline & muslim & 0 & 2 \\
\hline \multirow[t]{4}{*}{4} & MARITAL STATUS & & \\
\hline & single & 5 & 0 \\
\hline & Married & 35 & 37 \\
\hline & Widower & 0 & 3 \\
\hline \multirow[t]{4}{*}{5} & RESIDENTIAL AREA & & \\
\hline & rural & 32 & 19 \\
\hline & urban & 5 & 19 \\
\hline & semi urban & 3 & 2 \\
\hline \multirow[t]{4}{*}{6} & EDUCATIONAL QUALIFICATIONS & & \\
\hline & non-literate & 10 & 20 \\
\hline & primary level & 18 & 17 \\
\hline & secondary level & 11 & 3 \\
\hline
\end{tabular}




\begin{tabular}{|c|c|c|c|}
\hline & higher secondary level & 1 & 0 \\
\hline \multirow{4}{*}{7} & OCCUPATIONAL STATUS & & \\
\hline & unemployment & 11 & 14 \\
\hline & self employed & 5 & 5 \\
\hline & coolie & 24 & 21 \\
\hline \multirow[t]{4}{*}{8} & PATTERN OF WORK & & \\
\hline & secondary & 8 & 14 \\
\hline & moderate & 27 & 19 \\
\hline & heavy & 5 & 7 \\
\hline \multirow[t]{5}{*}{9} & FAMILY INCOME PER MONTH & & \\
\hline & Below Rs. 2000 & 1 & 8 \\
\hline & Rs. $2000-4000$ & 33 & 28 \\
\hline & Rs. $4001-6000$ & 4 & 4 \\
\hline & Above Rs. 6000 & 2 & 0 \\
\hline \multirow[t]{3}{*}{10} & FAMILY HISTORY OF CARDIAC DISEASE & & \\
\hline & yes & 0 & 9 \\
\hline & no & 40 & 31 \\
\hline \multirow[t]{3}{*}{11} & PREVIOUS HISTORY OF UNDERGOING ANGIOGR & & \\
\hline & yes & 5 & 5 \\
\hline & no & 35 & 35 \\
\hline \multirow[t]{4}{*}{12} & DURATION OF ILLNESS & & \\
\hline & Below 1 year & 35 & 13 \\
\hline & $1-3$ year & 5 & 25 \\
\hline & above 3 year & 0 & 2 \\
\hline \multirow[t]{3}{*}{13} & DIET PATTERN & & \\
\hline & vegetarian & 0 & 2 \\
\hline & non-vegetarian & 40 & 38 \\
\hline \multirow[t]{4}{*}{14} & ANY UNHEALTHY HABITS & & \\
\hline & smoking & 10 & 11 \\
\hline & alcoholism & 12 & 18 \\
\hline & tobacco & 18 & 11 \\
\hline \multirow[t]{3}{*}{15} & $\begin{array}{c}\text { SOURCE OF INFORMATION REGARDING CORONARY } \\
\text { ANGIOGRAM THROUGH }\end{array}$ & & \\
\hline & social media & 6 & 6 \\
\hline & mass media & 34 & 34 \\
\hline
\end{tabular}

Table 1: Frequency distribution table on demographic variables

Table 1 shows the distribution of the demographic variables among patients undergoing invasive therapeutic/ diagnostic procedure in cardiac wards. $\mathrm{n}=80$

\begin{tabular}{|c|c|c|}
\hline LEVEL OF SATISFACTION & \multicolumn{2}{|c|}{ GROUP } \\
\hline & CONTROL GROUP & EXPERIMENTAL GROUP \\
\hline Satisfied $=40-60$ & 0 & 40 \\
\hline Dissatisfied $=20-40$ & 25 & 0 \\
\hline Fully dissatisfied $=<20$ & 15 & 0 \\
\hline TOTAL & 40 & 40 \\
\hline
\end{tabular}

Table 2: frequency distribution table on patient level of satisfaction

Table 2 shows the level of satisfaction on routine method and video assisted method for invasive therapeutic/diagnostic procedures. In control group out of 40 samples, 25 samples were dissatisfied and 15 


\section{Open Access Journal of Pulmonary \& Respiratory Sciences}

samples were fully dissatisfied. In experimental group 40samples were satisfied and no dissatisfied, fully dissatisfied. In experimental group majority of the sample had only satisfied. It shows that video assisted consent method for invasive therapeutic/diagnostic procedures was effective. Hence stated hypothesis (HI) was accepted.

\begin{tabular}{|c|c|c|}
\hline LEVEL OF KNOWLEDGE & \multicolumn{2}{|c|}{ GROUP } \\
\hline & CONTROL GROUP & EXPERIMENTAL GROUP \\
\hline Inadequate knowledge & 40 & 0 \\
\hline Moderately adequate knowledge & 0 & 40 \\
\hline Adequate knowledge & 0 & 40 \\
\hline TOTAL & 40 & 0 \\
\hline
\end{tabular}

Table 3: frequency distribution table on level of knowledge.

$\mathrm{n}=80$

Table 3 shows the level of knowledge after getting consent through routine method and video assisted method among patients undergoing invasive therapeutic/diagnostic procedures. In control group out of 40 samples, 40 samples had inadequate knowledge. In experimental group 40samples had adequate knowledge and no moderately adequate knowledge and inadequate knowledge. In experimental group majority of the sample had only adequate knowledge. It shows that routine method and video assisted method for invasive therapeutic/diagnostic procedures was effective.

\begin{tabular}{|c|c|c|c|c|}
\hline $\begin{array}{c}\text { LEVEL OF } \\
\text { SATISFACTION }\end{array}$ & MEAN & SD & $\begin{array}{c}\text { MANN-WHITNEY } \\
\text { TEST }\end{array}$ & P-VALUE \\
\hline CONTROL GROUP & 19.55 & 1.45 & & $<0.001^{*}$ \\
\hline EXPERIMENTAL GROUP & 57.93 & 0.83 & 7.802 & $<2$ \\
\hline
\end{tabular}

Table 4: Comparison of the mean, SD of satisfaction level.

Table 4 shows the mean value for satisfaction was 19.55 with standard deviation of 14.5 in control group and mean value was 57.93 with standard deviation of 0.83 in experimental group.

\begin{tabular}{|c|c|c|c|c|}
\hline LEVEL OF KNOWLEDGE & MEAN & SD & MANN-WHITNEY TEST & P-VALUE \\
\hline CONTROL GROUP & 3.52 & 0.99 & & \\
\hline EXPERIMENTAL GROUP & 17.18 & 0.84 & 7.844 & $<0.001^{*}$ \\
\hline
\end{tabular}

Table 5: Comparison of the mean, SD of knowledge score.

Table 5 shows the mean value for knowledge was 3.52 with standard deviation of 0.99 in control group and mean value was 17.8 with standard deviation of 0.84 in experimental group.

The improvement was tested by paired ' $t$ ' test which was found significant at $\mathrm{p}<0.001$ implicating the effectiveness of video assisted informed consent.

\section{Discussion}

The majority of people develop cardiovascular disease in some course of their life. Cardiovascular disease is a major disease which affects the human vital organs. It cannot control only through medical treatment and also through proper diet, exercise. Since informed consent is a core clinical procedure. Investigator was assessing the effectiveness of informed consent process through routine method vs video assisted method on level of satisfaction and cognition among patients undergoing invasive therapeutic / diagnostic procedure.

The study was conducted by using true experimental (post test only) design. The study was conducted in cardiac wards, MGMC@RI, puducherry. The total sample size was 80 , where 40 in experimental group and 40 in control group. The data is obtained through the structured questionnaire and satisfaction is asses through the standardized satisfactory tools. Then it was analyzed by using evaluative and inferential statistics.

The objective of the study was to assess and compare effectiveness of the patient level of satisfaction and 


\section{Open Access Journal of Pulmonary \& Respiratory Sciences}

cognition regarding informed consent by routine method vs video assisted method for therapeutic/diagnostic procedures.

a) The mean value for knowledge was 3.52 with standard deviation of 0.99 in control group and mean value was 17.8 with standard deviation of 0.84 in experimental group.

b) The mean value for satisfaction was 19.55 with standard deviation of 14.5 in control group and mean value was 57.93 with standard deviation of 0.83 in experimental group.

The improvement was tested by paired ' $t$ ' test which was found significant at $\mathrm{p}<0.001$ implicating the effectiveness of video assisted informed consent.

\section{Conclusion}

Getting an informed consent is a core clinical procedure. In today's dynamic health systems, technology plays an important role in education and nursing work. Levels of satisfaction from the patient's necessitate the adoption of video assisted informed consent for invasive therapeutic/diagnostic procedure in this technological era. The video assisted consent process may give patient a better understanding and has the potential to minimize therapeutic misconception. The present study revealed that the video assisted consent process is effective and satisfy the patient when compare to routine method.

\section{References}

1. Grossman W (1988) Heart disease: A textbook of cardiovascular medicine. Philadelphia, USA: WB Saunders.
2. Hillis (1984) The guide to cardiology. Newyork, USA: Wiley.

3. Lundin L, Sargent T, Laura B (1998) Research utilization and improvement in outcomes after diagnostic cardiac catheterisation. Critical Care Nursing 18(5): 30-39.

4. Lamarche D, Taddeo R, Pepler C (1998) The preparation of patients for cardiac surgery. Clinical nursing research 7(4): 390-405.

5. Almas A, Hameed A (2008) Knowledge of coronary artery disease risk factors and coronary intervention among university students. J Pak Med Assoc 58(10): 553-557.

6. Lyons AC, Fanshawe C (2002) Knowledge, communication and expectancies of cardiac catheterization: The patient's perspective. Psychology, health and medicine 7(4): 461-467.

7. Gallagher R, Trotter R (2010) Preprocedural concerns and anxiety assessment in patients undergoing coronary angiogram and percutaneous interventions. European journal of cardiovascular nursing 9(1): 3844.

8. Senay Uzun, Vural H (2008) State and trait anxiety levels before coronary angiography. Journal of clinical nursing 17(5): 602-607.

9. Verges M, Leclercq F, Davy JM, Piot C, Gervasoni R, et al. (2011) Are patients undergoing coronary angiography well-informed? Prospective evaluation of the effectiveness of written information. Ann Cardiol Angeiol 60(2): 77-86. 